\title{
Effects of Cerebral Ischemia on Levels of Vascular Endothelial Growth Factor (VEGF) and Its Soluble Receptors: A Possible Link to Angiogenesis in Arteriovenous Malformations
}

\author{
Birol BAYRAKTAR ${ }^{1}$, Dursun TURKOZ1 ${ }^{1}$ Aytac TURKOZ², Ahmet KARKUCAK¹ \\ ${ }^{1}$ University of Health Sciences, Samsun Education and Research Hospital, Department of Neurosurgery, Samsun, Turkey \\ ${ }^{2}$ Medibafra Hospital, Department of Neurosurgery, Samsun, Turkey \\ Corresponding author: Dursun TURKOZ turkozdursun@gmail.com
}

\section{ABSTRACT}

AIM: To investigate the levels of vascular endothelial growth factor (VEGF) in the brain, and its soluble forms, namely sVEGFR1 and sVEGFR2, levels in the plasma of rats after cerebral ischemia.

MATERIAL and METHODS: Rats were divided into three groups as follows: Group 1: Sham-operated group, Group 2: Complete occlusion of the right carotid artery, Group 3: Complete occlusion of the right carotid artery and temporary occlusion of the left carotid artery for $10 \mathrm{~min}$. Blood samples were collected on days 0 and 10 prior to the sacrification to measure the sVEGFR 1 and sVEGFR2 levels. On day 10, animals were sacrificed, and brain tissue was collected to analyze VEGF expression.

RESULTS: Postoperative sVEGFR1 levels reduced significantly in Group 3, while it remained stable in other groups. sVEGFR2 levels did not change in any group. Although VEGF staining scores in the groups that underwent ischemia procedures increased compared to group 1, no significant differences were observed.

CONCLUSION: Decreased levels of SVEGFR1 can be a mechanism contributing to angiogenesis in arteriovenous malformations by increasing the levels of VEGF available to bind membrane-bound VEGFRs.

KEYWORDS: Angiogenesis, Arteriovenous malformations, Cerebral ischemia, Vascular endothelial growth factor, VEGF, Rats

ABBREVIATIONS: AVM: Arteriovenous malformations, BBB: Blood-brain barrier, C/IR: Cerebral ischemia/reperfusion, VEGF: Vascular endothelial growth factor, VEGFR: Vascular endothelial growth factor receptor

\section{INTRODUCTION}

S troke, including both ischemic (cerebral ischemia) and hemorrhagic, causes immediate cessation of the supply of oxygen and glucose to the brain and is a major contributor to mortality and disability worldwide (5). Majority of the ischemic strokes are due to thromboembolic conditions with the most common origin of the embolism being large artery atherosclerosis and cardiac conditions. On the other hand, small vessel disease, arterial dissection, vasculitis, patent foramen ovale with paradoxical embolism, and hematological diseases are less common but prevalent causes of it (5). Although neurological and functional abnormalities due to ischemia can be significantly prevented by adequate and timely measures (3) and recovery of blood circulation in the tissue, brain injury, including cerebral edema that leads to neuronal damage and consequently to cell death, are unavoidable after cerebral ischemia / reperfusion (C/IR) (34).

Arteriovenous malformations (AVMs) are vascular anomalies characterized by direct connections between the arterial and venous circulations that lack a connection through capillaries
Birol BAYRAKTAR (D) : 0000-0003-4546-2797 Dursun TURKOZ : (D): 0000-0003-3599-0895
Aytac TURKOZ (D) : 0000-0002-6520-2602

Ahmet KARKUCAK (D) : 0000-0003-2522-1822 
(32). They can be either congenital (30) or acquired (44), and risk of hemorrhage in the cerebral AVMs is reported to be $2-4 \%$ annually, while the risk of mortality and neurological disability were reported as 5-25\% and 10-50\%, respectively $(10,31,40)$. Among the management modalities of AVMs, including microsurgical resection, radiosurgery and endovascular embolization (36), preoperative endovascular embolization is usually preferred before other surgical approaches (33). On the other hand, the aim of curative embolization is to achieve the complete obliteration of the AVM nidus resulting in the restoration of normal arterial-to-venous flow (35). However, performing curative embolization to treat AVM is still in debate due to the risks of complication (9) and recurrence of the AVM (1).

Embolization of the AVM can lead to ischemia of the surrounding tissue, (22) altering the microenvironment considerably. Reduced blood flow disrupts energy equilibrium, causing excitotoxicity in neurons, astrocytes, microglia, and oligodendrocytes. In turn, there is an increase in the release of trophic factor and proinflammatory cytokines, which eventually induces an inflammatory response (11). The blood-brain barrier (BBB) that is composed of endothelial cells is disrupted due to ischemia and the induced inflammatory response. Proinflammatory cytokine release, together with the inducible nitric oxide synthase, causes neuronal damage and cell death (11). One of the suggested mechanisms for the recurrence of AVMs is angiogenesis as AVM is the result of dynamic processes and continuous remodeling (41). Mechanisms of AVM embolization-induced angiogenesis include hypoxia-, inflammatory-, and hemodynamic-mediated angiogenesis, all leading to increased revascularization of the AVM (4).

Vascular endothelial growth factor (VEGF) is an important regulator of vascular permeability and angiogenesis (18). VEGF exerts its activity mainly by binding its receptors, VEGF receptor 1 (VEGFR1), 2 (VEGFR2), and 3 (VEGFR3), then modulating the downstream pathways (18). Aside from these receptors, two soluble receptors for VEGF, sVEGFR1, and sVEGFR2, also bind to VEGF and play an antagonistic role $(2,19)$. Although VEGF is known to regulate various processes for the tissue to adapt to ischemic conditions $(7,29)$, it also contributes to the adverse outcomes of ischemia or stroke, including edema formation (23) and BBB disruption (42).

High VEGF and VEGFR expressions found in tissue surrounding the ischemic area suggest their role in angiogenesis in AVM $(25,38)$. Sure et al. found significantly higher VEGF levels in the AVM after embolization and suggested that it may be a result of the hypoxia, which is induced by embolization (39). Another study showed decreased plasma VEGF levels after AVM resection; however, VEGF levels were significantly elevated 30 days after the procedure, suggesting its role in angiogenesis (24). It was suggested that inhibition of VEGF activity may be an effective method to prevent AVM recurrence and may lead to a regression of AVM size (41). Recanalization after the obliteration of AVM is a rare condition (20). Therefore, the present study aimed to investigate the expression levels of VEGF and its soluble receptors, sVEGFR1 and sVEGFR2, in the rat model of carotid artery occlusion with the hypothesis that the occlusion of the main arteries is the major contributor leading to revascularization in recurrent AVMs.

\section{MATERIAL and METHODS}

\section{Animal Husbandry, Experimental Groups, and Surgical Procedures}

Experiments were performed according to the Health Guidelines for the Care and Use of Laboratory Animals of the National Health Institute and approved by the local animal research ethics committee. Eighteen female Wistar-Albino rats weighing 230-260 g were housed under controlled temperatures $\left(21 \pm 1^{\circ} \mathrm{C}\right)$ and controlled lighting conditions (12/12-h light/dark cycle). Standard rat chow and tap water were provided ad libitum.

Surgical anesthesia of the animals was achieved by intraperitoneal (ip) injection of a mixture of $35 \mathrm{mg} / \mathrm{kg}$ bodyweight (bw) ketamine (Ketalar, Parke-Davis. Eczacibasi, Turkey) and $5 \mathrm{mg} / \mathrm{kg}$ bw xylazine (Rompun, Bayer, Turkey). Animals were divided into three groups as follows: Group 1: Sham-operated group, Group 2: Animals only underwent complete occlusion of the right carotid artery procedure, and Group 3: Animals underwent complete occlusion of the right carotid artery procedure and temporary occlusion of the left carotid artery for a period of $10 \mathrm{~min}$ by Yasargil aneurysm clip (Aesculap FE $721 \mathrm{~K}$ ) with a 63-g closing force applied to create a standard trauma, according to the two-vessel occlusion model that was described previously (12). For the complete occlusion of the arteries, surgical sutures made of silk $(3 / 0)$ were used. All measures to prevent damage to the carotid arteries were taken during the procedures.

Animals were placed in their cages at the end of the recovery period of the surgery and given $40 \mathrm{mg} / \mathrm{kg} / \mathrm{day}$ cephazolin sodium (Sefazol, Mustafa-Nevzat, Turkey) by ip injection for the first three days of the follow-up period to prevent surgical site infection,. At the end of the follow-up period (10 days), animals were sacrificed by intravenous injection of $100 \mathrm{mg} /$ $\mathrm{kg}$ phenobarbital.

\section{Serum Collection and Enzyme-linked Immunosorbent Assay (ELISA)}

Blood samples drawn from the tail vein of the rats were collected in 2-mL blood collection tubes containing EDTA as the anticoagulant (367842, BD Diagnostics) prior to the surgery (day 0 ) and at the last day of the follow-up period (day 10) under general anesthesia. Blood samples were centrifuged at 3,000 x RPM for 10 minutes, then serum was collected and stored at $-80^{\circ} \mathrm{C}$ until use.

sVEGFR1 (E0147r, USCNLIFETM ${ }^{\mathrm{T}}$, China) and sVEGFR2 (E0148r, USCNLIFETM, China) levels were spectrophotometrically determined by sandwich ELISA method according to the manufacturer's instructions.

\section{Histopathological Evaluations}

After sacrificing the animals on the $10^{\text {th }}$ day, brains were dissected and fixed in $10 \%$ formaldehyde, washed with tap water, dehydrated using increasing concentrations of ethanol 
$(70 \%, 80 \%, 90 \%$, and $96 \%)$, and incubated in xylene. After embedding the tissues in paraffin at $60^{\circ} \mathrm{C}$, coronal sections were taken starting at $-0.2 \mathrm{~mm}$ from the bregma with a thickness of $2 \mu \mathrm{m}$ by targeting the caudoputamen. Then, these were incubated at $60^{\circ} \mathrm{C}$ for $45 \mathrm{~min}$. After incubation, sections were transferred in xylene and then in increasing concentrations of ethanol $(70 \%, 80 \%, 90 \%$, and $96 \%)$, washed with tap water, and stained with hematoxylin \& eosin (H\&E). Ischemic areas were investigated under light microscopy, and then sections were prepared for immunohistochemical examinations.

\section{Immunohistochemical Evaluations}

After embedding the tissue in paraffin for 12 hours, coronal sections with a thickness of $2 \mu \mathrm{m}$ were taken, placed on lysine-coated slides, and incubated at $70^{\circ} \mathrm{C}$ for $1 \mathrm{~h}$. Then, the sections were incubated in xylene for $20 \mathrm{~min}$ for deparaffinizing, dehydrated in decreasing concentrations of ethanol $(96 \%, 90 \%, 80 \%$, and $70 \%)$, and washed with tap water. The sections were boiled in antigen retrieval buffer (Tris-EDTA buffer with $0.5 \%$ Tween-20, $\mathrm{pH}=8.0$ ) for $7 \mathrm{~min}$ and rinsed in Tris buffer (Tris-buffered saline with $0.5 \%$ Tween-20) for $5 \mathrm{~min}$. Endogenous peroxide activity was blocked by incubating the sections in $\mathrm{H}_{2} \mathrm{O}_{2}$ for $15 \mathrm{~min}$, and then, the sections were rinsed with Tris buffer. Sections were blocked in UV block solution for $5 \mathrm{~min}$ and incubated with anti-VEGF antibody (1:100; \#RB-222-P0, Thermo Scientific) at room temperature for $1 \mathrm{~h}$. Then, sections were washed with Tris buffer, incubated with anti-rabbit secondary antibody for 20 min, washed with Tris buffer, and incubated with horseradish peroxidase solution for $20 \mathrm{~min}$. Then, sections were washed with Tris buffer, stained with diaminobenzidine (DAB) for $7 \mathrm{~min}$, washed with water, and stained with Mayer's H\&E solution for $5 \mathrm{sec}$. After washing with water, sections were incubated in increasing concentrations of ethanol $(70 \%, 80 \%, 90 \%$, and $96 \%$ ), incubated in xylene for $5 \mathrm{~min}$, and subsequently, imaging was performed. The sections were scored as follows: No staining $=0$, mild staining $=1$, moderate staining $=2$, and strong staining $=3$.

\section{Statistical Analyses}

GraphPad Prism 7.0 (GraphPad Software, USA) was used for statistical evaluations. All data were expressed as mean \pm standard deviation (SD). Normal distribution of each dataset was investigated by using the Shapiro-Wilk normality test. Significant differences between the initial and final concentrations of sVEGFR1 and sVGFR2 within the groups were investigated by using paired t-test in the case that the data were normally distributed, while data without normal distribution were compared with the Wilcoxon matchedpairs signed rank test. The differences in the initial and final concentrations of sVEGFR1 and sVGFR2 between the groups as well as the bodyweight differences were analyzed by one-way ANOVA followed by Tukey's multiple comparison tests in the case that the data were normally distributed, while the data without normal distribution were analyzed by using Kruskal-Wallis followed by Dunn's multiple comparison tests. A p-value lower than 0.05 was considered statistically significant.

\section{RESULTS}

The mean bodyweight of the animals in group 1,2, and 3 were $237.32 \pm 8.49 \mathrm{~g}, 240.01 \pm 6.87 \mathrm{~g}$, and $239.15 \pm 7.52 \mathrm{~g}$, respectively $(p>0.05)$. There were no differences between the initial and final sVEGFR1 levels between the groups ( $p>0.05$; Figure 1A). No significant changes in sVEGFR1 levels were observed in groups 1 and 2 at day 10, while sVEGFR1 levels were found to be significantly reduced in group $3(p=0.022$; Figure 1A). On the other hand, no significant differences in sVEGFR2 levels between the groups were detected at either day 0 or day 10 , and sVEGFR2 levels were not significantly altered within the groups after the procedure $(p>0.05$; Figure 1B).

H\&E staining revealed the development of vascular structures and increased numbers in groups 2 and 3. Moreover, ischemic neurons were mildly swollen, and loss of Nissl substance as well as elevated cytoplasmic eosinophilia and pyknosis were observed in these groups. On the other hand, VEGF expressions investigated by immunohistochemistry (IHC) staining of the brain showed that although group 1 exhibited lower staining than groups 2 and 3 , there were no significant differences between the groups (Figure 2A-D; $p>0.05$ ).
(A)

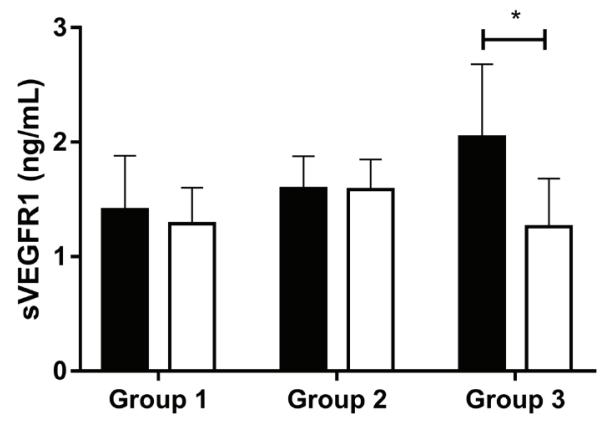

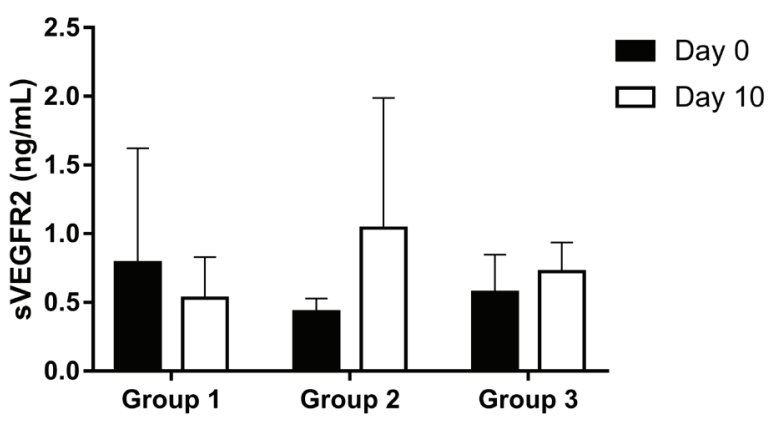

Figure 1: A) sVEGFR1 and B) sVEGFR2 levels in group 1, 2, and 3 before and after the interventions, respectively. Data are mean \pm SD $\left(n=6\right.$ in each group; $\left.{ }^{*} p<0.05\right)$. 


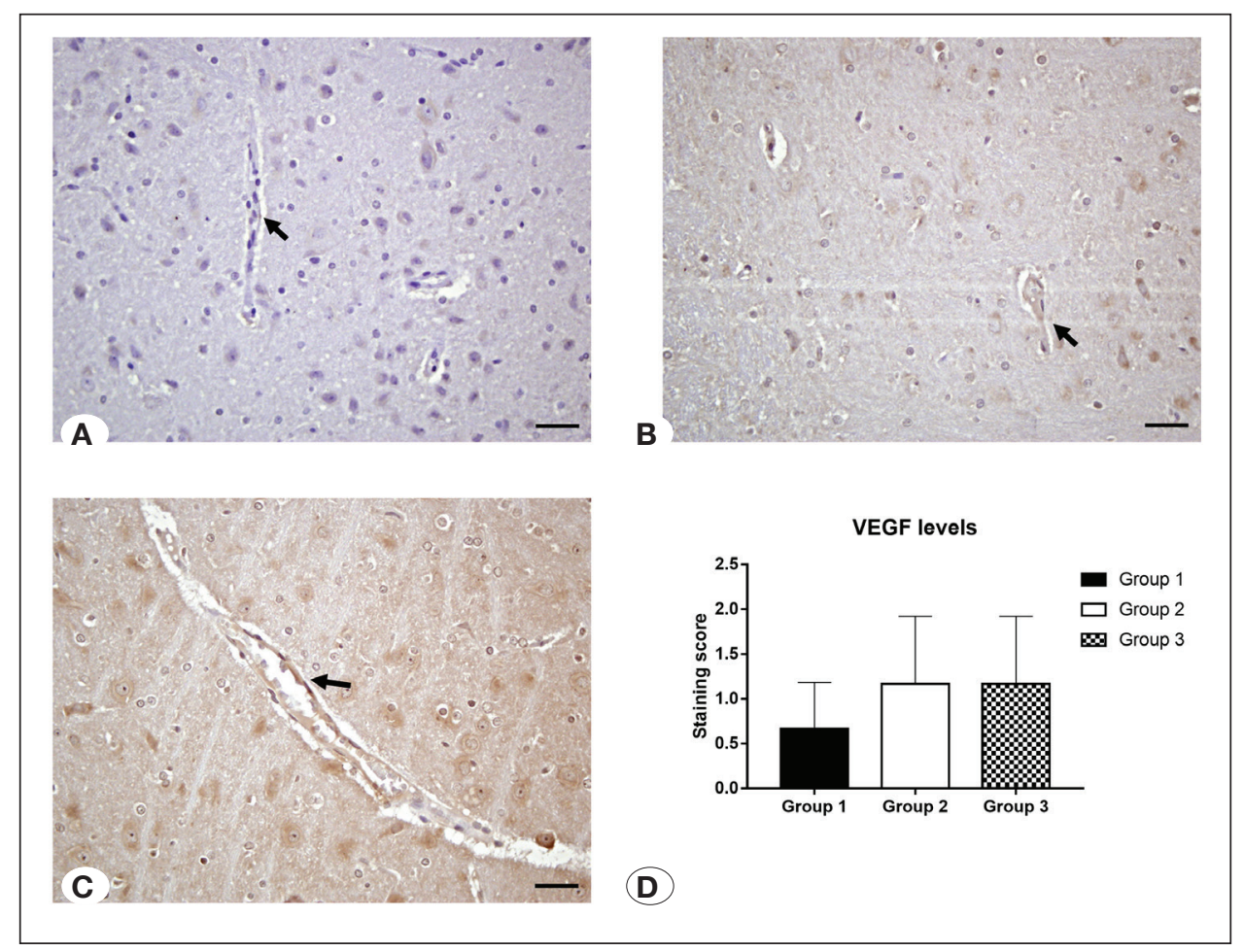

Figure 2: Representative figures for VEGF expression in (A) group 1, (B) group 2, and (C) group 3, and (D) $\mathrm{IHC}$ staining scores. Black arrows indicate the VEGF staining in the endothelial cells. Data are mean \pm SD $(\mathrm{n}=6$ in each group). Magnification $=$ $400 \mathrm{x}$ and Scale bars $=100 \mu \mathrm{m}$

\section{DISCUSSION}

AVMs in the brain are extremely dynamic as their growth, remodeling, and regression are sustained (4). The etiology of the AVM remains unclear; however, both genetic and angiogenic stimulations are thought to play roles in the development of pathogenesis (26). On the other hand, angiogenic factors are thought to be the major factors in AVM development $(6,14,15,21,28)$. Therefore, in the present study, we aimed to investigate the effect of cerebral artery occlusion on sVEGFR1, sVEGFR2, and VEGF levels as well as angiogenesis in rats.

Under various physiological and pathological conditions, endogenous VEGF assists in the development of compensatory neovascularization. In AVMs, endothelial cells were reported to express increased amounts of VEGF isoforms and VEGFR1 (25). Previous studies showed elevated levels of local VEGF in AVMs (13) and circulating VEGF (37). Another study reported decreased lower VEGF plasma levels and higher local expression around the niduses in AVM patients compared to the control group (24). In the present study, both ischemia groups were found to have higher levels of VEGF in the brain; however, there were no significant differences between the groups. On the other hand, histopathological analyses revealed increased vascularization in the ischemic area after reperfusion, suggesting a possible role of elevated VEGF in the vascularization of the ischemic area. However, a direct link between elevated VEGF expression, angiogenesis, and AVM formation has not yet been demonstrated.

sVEGFR1 and sVEGFR2 are the soluble forms of VEGFRs and have been reported to counteract the angiogenesis process
$(8,27)$. In our study, significant downregulation of the sVEGFR1 was observed in the group that underwent temporary carotid artery occlusion (group 3), while no significant differences were found in other groups. In addition, sVEGFR2 levels remained unchanged. In a previous study, membrane-bound VEGFR1 was indicated to be increased upon hindlimb ischemia/ reperfusion, while VEGFR2 levels were reduced, most likely due to modulatory/proangiogenic activities of both receptors (16). The reason for decreased sVEGFR1 in the ischemia/ reperfusion group may be a compensatory mechanism for the increased angiogenic activity (17) as VEGF may bind to the membrane-bound VEGFR (16) and induce angiogenesis. Elevated VEGF and VEGFR levels suggest angiogenic activity in AVMs leading to recurrence. Therefore, decreased levels of sVEGFR1 may be a contributing mechanism to the recurrence of AVMs after embolization.

There are limitations in this study. First, an experimental animal model was used in this study to simulate the ischemic conditions after endovascular embolization in AVM by carotid artery occlusion. Other genetic or original models to simulate AVM conditions in animal models are also available (43). Secondly, animals could be monitored postoperatively for a longer period, and behavioral experiments could be conducted for assessment. Moreover, longer follow-up period may result in more pronounced changes in both histology and sVEGFR levels.

\section{CONCLUSION}

In conclusion, decreased levels of SVEGFR1 may be a mechanism contributing to angiogenesis by increasing the availability of VEGF that can bind to membrane-bound 
VEGFRs. Further studies are needed to elucidate these mechanisms by investigating the activities of VEGFRs in combination with the sVEGFR inactivation. On the other hand, development and administration of antiangiogenic agents by using materials during the embolization of AVMs may increase the success rates of the AVM treatments and decrease the recurrence.

\section{ACKNOWLEDGEMENTS}

Preparation for publication of this article is partly supported by Turkish Neurosurgical Society.

\section{REFERENCES}

1. Akakin A, Ozkan A, Akgun E, Koc DY, Konya D, Pamir MN, Kilic T: Endovascular treatment increases but gamma knife radiosurgery decreases angiogenic activity of arteriovenous malformations: An in vivo experimental study using a rat cornea model. Neurosurgery 66:121-130, 2010

2. Aweimer A, Stachon T, Tannapfel A, Köller M, Truss MC, Stachon A: Regulation of soluble VEGFR-2 secreted by microvascular endothelial cells derived from human BPH. Prostate Cancer Prostatic Dis 15:157-164, 2012

3. Berkhemer OA, Fransen PSS, Beumer D, van den Berg LA, Lingsma HF, Yoo AJ, Schonewille WJ, Vos JA, Nederkoorn PJ, Wermer MJH, van Walderveen MAA, Staals J, Hofmeijer J, van Oostayen JA, Lycklama à Nijeholt GJ, Boiten J, Brouwer PA, Emmer BJ, de Bruijn SF, van Dijk LC, Kappelle LJ, Lo $R H$, van Dijk EJ, de Vries J, de Kort PLM, van Rooij WJJ, van den Berg JSP, van Hasselt BAAM, Aerden LAM, Dallinga RJ, Visser MC, Bot JCJ, Vroomen PC, Eshghi O, Schreuder THCML, Heijboer RJJ, Keizer K, Tielbeek AV, den Hertog HM, Gerrits DG, van den Berg-Vos RM, Karas GB, Steyerberg EW, Flach HZ, Marquering HA, Sprengers MES, Jenniskens SFM, Beenen LFM, van den Berg R, Koudstaal PJ, van Zwam WH, Roos YBWEM, van der Lugt $A$, van Oostenbrugge RJ, Majoie CBLM, Dippel DWJ: A randomized trial of intraarterial treatment for acute ischemic stroke. New England Journal of Medicine 372:11-20, 2014

4. Buell TJ, Ding D, Starke RM, Webster Crowley R, Liu KC: Embolization-induced angiogenesis in cerebral arteriovenous malformations. J Clin Neurosci 21:1866-1871, 2014

5. Campbell BCV, De Silva DA, Macleod MR, Coutts SB, Schwamm LH, Davis SM, Donnan GA: Ischaemic stroke. Nature Reviews Disease Primers 5:70, 2019

6. Caranfa JT, Baldwin MT, Rutter CE, Bulsara KR: Synchronous cerebral arteriovenous malformation and lung adenocarcinoma carcinoma brain metastases: A case study and literature review. Neurochirurgie 65:36-39, 2019

7. Dzietko M, Derugin N, Wendland MF, Vexler ZS, Ferriero DM: Delayed VEGF treatment enhances angiogenesis and recovery after neonatal focal rodent stroke. Translational Stroke Research 4:189-200, 2013

8. Ebos JML, Bocci G, Man S, Thorpe PE, Hicklin DJ, Zhou D, Jia X, Kerbel RS: A naturally occurring soluble form of vascular endothelial growth factor receptor 2 detected in mouse and human plasma. Mol Cancer Res 2:315-326, 2004
9. Ellis JA, Lavine SD: Role of embolization for cerebral arteriovenous malformations. Methodist Debakey Cardiovasc J 10:234-239, 2014

10. Friedlander RM: Clinical practice. Arteriovenous malformations of the brain. N Engl J Med 356:2704-2712, 2007

11. George PM, Steinberg GK: Novel stroke therapeutics: Unraveling stroke pathophysiology and its impact on clinical treatments. Neuron 87:297-309, 2015

12. Ginsberg MD: Models of cerebral ischemia in the rodent. In: Schurr A, Rigor BM (eds), Cerebral Ischemia and Resuscitation. Boca Raton, Florida: CRC Press, 1990:1-27

13. Hashimoto T, Wu Y, Lawton MT, Yang G-Y, Barbaro NM, Young WL: Coexpression of angiogenic factors in brain arteriovenous malformations. Neurosurgery 56:1058-1065, 2005

14. Herzig R, Bogousslavsky J, Maeder P, Maeder-Ingvar M, Reichhart M, Urbano LA, Leemann B: Intracranial arterial and arteriovenous malformations presenting with infarction. Lausanne Stroke Registry study. Eur J Neurol 12:93-102, 2005

15. Hofman M, Jamróz T, Kołodziej I, Jaskólski J, Ignatowicz A, Jakutowicz I, Przybyłko N, Kocur D, Baron J: Cerebral arteriovenous malformations - usability of Spetzler-Martin and Spetzler-Ponce scales in qualification to endovascular embolisation and neurosurgical procedure. Pol $\mathrm{J}$ Radiol 83:e243-e247, 2018

16. Imoukhuede PI, Dokun AO, Annex BH, Popel AS: Endothelial cell-by-cell profiling reveals the temporal dynamics of VEGFR1 and VEGFR2 membrane localization after murine hindlimb ischemia. Am J Physiol Heart Circ Physiol 304:H1085-H1093, 2013

17. Kanazawa M, Takahashi T, Ishikawa M, Onodera $\mathrm{O}$, Shimohata T, del Zoppo GJ: Angiogenesis in the ischemic core: A potential treatment target? J Cereb Blood Flow Metab 39:753-769, 2019

18. Karaman S, Leppänen VM, Alitalo K: Vascular endothelial growth factor signaling in development and disease. Development 145(14):dev151019, 2018

19. Kendall RL, Wang G, Thomas KA: Identification of a natural soluble form of the vascular endothelial growth factor receptor, FLT-1, and its heterodimerization with KDR. Biochem Biophys Res Commun 226:324-328, 1996

20. Khalil A, Kok HK, Brennan P, Javadpour M, Rawluk D, Asadi H: Brain arteriovenous malformation recurrence-recanalization or rebirth? World Neurosurg 94:581.e581-581.e584, 2016

21. Khandelwal A, Chaturvedi A, Singh GP, Mishra RK: Intractable brain swelling during cerebral arteriovenous malformation surgery due to contralateral acute subdural haematoma. Indian J Anaesth 62:984-987, 2018

22. Khurana A, Hangge TP, Albadawi H, Knuttinen MG, Alzubaidi JS, Naidu GS, Kriegshauser SJ, Oklu R, Chong WB: The use of transarterial approaches in peripheral arteriovenous malformations (AVMs). J Clin Med 7(5):109, 2018

23. Kim E, Yang J, Park KW, Cho S: Inhibition of VEGF signaling reduces diabetes-exacerbated brain swelling, but not infarct size, in large cerebral infarction in mice. Transl Stroke Res 9:540-548, 2018 
24. Kim GH, Hahn DK, Kellner CP, Hickman ZL, Komotar RJ, Starke RM, Mack WJ, Mocco J, Solomon RA, Connolly ES, Jr: Plasma levels of vascular endothelial growth factor after treatment for cerebral arteriovenous malformations. Stroke 39:2274-2279, 2008

25. Koizumi T, Shiraishi T, Hagihara N, Tabuchi K, Hayashi T, Kawano T: Expression of vascular endothelial growth factors and their receptors in and around intracranial arteriovenous malformations. Neurosurgery 50:117-126, 2002

26. Komiyama M: Pathogenesis of brain arteriovenous malformations. Neurol Med Chir 56:317-325, 2016

27. Lamszus K, Ulbricht U, Matschke J, Brockmann MA, Fillbrandt $R$, Westphal M: Levels of soluble vascular endothelial growth factor (VEGF) receptor 1 in astrocytic tumors and its relation to malignancy, vascularity, and VEGF-A. Clin Cancer Res 9:1399-1405, 2003

28. Li W, Sun Q, Duan X, Yi F, Zhou Y, Hu Y, Yao L, Xu H, Zhou L: Etiologies and risk factors for young people with intracerebral hemorrhage. Zhong Nan Da Xue Xue Bao Yi Xue Ban 43:12461250, 2018

29. Ma Y, Zechariah A, Qu Y, Hermann DM: Effects of vascular endothelial growth factor in ischemic stroke. J Neurosci Res 90:1873-1882, 2012

30. Manjunath SM, Shetty S, Moon NJ, Sharma B, Metta KK, Gupta N, Goyal S, Singh S: Arteriovenous malformation of the oral cavity. Case Rep Dent 2014:353580, 2014

31. Ogilvy CS, Stieg PE, Awad I, Brown RD, Jr., Kondziolka D, Rosenwasser R, Young WL, Hademenos G, Special Writing Group of the Stroke Council ASA: AHA Scientific Statement: Recommendations for the management of intracranial arteriovenous malformations: A statement for healthcare professionals from a special writing group of the Stroke Council, American Stroke Association. Stroke 32:1458-1471, 2001

32. Pandhare MN, Jyoti DB, Mandale MS, Suresh RB: Acquired arteriovenous malformation of lip occurring as an occupational hazard: A case report with review of literature. J Oral Maxillofac Pathol 22:287, 2018

33. Plasencia AR, Santillan A: Embolization and radiosurgery for arteriovenous malformations. Surg Neurol Int 3:S90-S104, 2012

34. Renú A, Laredo C, Tudela R, Urra X, Lopez-Rueda A, Llull L, Oleaga L, Amaro S, Chamorro Á: Brain hemorrhage after endovascular reperfusion therapy of ischemic stroke: A threshold-finding whole-brain perfusion CT study. J Cereb Blood Flow Metab 37:153-165, 2015
35. Richling B, Killer M: Endovascular management of patients with cerebral arteriovenous malformations. Neurosurg Clin N Am 11(1):123-145, ix, 2000

36. Richling B, Killer M, Al-Schameri AR, Ritter L, Agic R, Krenn M: Therapy of brain arteriovenous malformations: Multimodality treatment from a balanced standpoint. Neurosurgery 59:S148-S113, 2006

37. Sandalcioglu IE, Wende D, Eggert A, Müller D, Roggenbuck U, Gasser T, Wiedemayer H, Stolke D: Vascular endothelial growth factor plasma levels are significantly elevated in patients with cerebral arteriovenous malformations. Cerebrovasc Dis 21:154-158, 2006

38. Sure U, Butz N, Schlegel J, Siegel AM, Wakat JP, Mennel $\mathrm{HD}$, Bien S, Bertalanffy $\mathrm{H}$ : Endothelial proliferation, neoangiogenesis, and potential de novo generation of cerebrovascular malformations. J Neurosurg 94:972-977, 2001

39. Sure U, Butz N, Siegel AM, Mennel HD, Bien S, Bertalanffy H: Treatment-induced neoangiogenesis in cerebral arteriovenous malformations. Clin Neurol Neurosurg 103:29-32, 2001

40. van Beijnum J, van der Worp HB, Schippers HM, van Nieuwenhuizen O, Kappelle LJ, Rinkel GJE, Berkelbach van der Sprenkel JW, Klijn CJM: Familial occurrence of brain arteriovenous malformations: A systematic review. J Neurol Neurosurg Psychiatry 78:1213-1217, 2007

41. Vernimmen FJAI: Vascular endothelial growth factor blockade: A potential new therapy in the management of cerebral arteriovenous malformations. Journal of Medical Hypotheses and Ideas 8:57-61, 2014

42. Wu L, Ye Z, Pan Y, Li X, Fu X, Zhang B, Li Y, Lin W, Li X, Gao $Q$ : Vascular endothelial growth factor aggravates cerebral ischemia and reperfusion-induced blood-brain-barrier disruption through regulating LOC102640519/HOXC13/ZO-1 signaling. Experimental Cell Research 369:275-283, 2018

43. Xu M, Xu H, Qin Z: Animal models in studying cerebral arteriovenous malformation. BioMed Research International 2015:178407-178407, 2015

44. Yang $\mathrm{CH}$, Ohara $\mathrm{K}$ : Acquired digital arteriovenous malformation: A report of three cases and study with epiluminescence microscopy. Br J Dermatol 147:1007-1011, 2002 